\title{
Osteoporosis in the Cohen Diabetic Rat: Correlation Between Histomorphometric Changes in Bone and Microangiopathy
}

\author{
Gail Amir, Eliezer Rosenmann, Yoav Sherman, Ziv Greenfeld, Zvi Ne'eman, and \\ Aharon Mordechai Cohen
}

Department of Pathology (GA, YS, AMC) and Diabetic Unit (AMC-deceased), Hadassah Medical Center and Hebrew University, Department of Pathology (ER), Sha'ari-Zedek Medical Center, and Departments of Medicine (ZG) and Pathology (ZN), Hadassah University Hospital, Mount Scopus, Jerusalem, Israel

\begin{abstract}
SUMMARY: Osteoporosis is well documented in type I diabetes, but its occurrence is controversial in type II diabetes. Microangiopathy is a major complication of type I and type II diabetes. We studied bone and microvascular changes in the Cohen diabetic rat, a unique nonobese model of noninsulin-dependent diabetes mellitus. The aim of this study was to find whether there is a temporal correlation between the onset of these two complications. The diabetic rats were divided into three groups (A, B, and C) according to duration of diabetes (2 months, 3 months, and 7 to 8 months, respectively). Trabecular bone area was assessed by computerized image analysis and microangiopathy by means of renal function tests, histologic examination of the kidneys, and ultrastructural measurement of the width of capillary basement membranes. Bone density of the distal femur and vertebra was significantly reduced in the diabetic rats relative to the control rats in all three groups (Group A femur: $11.5 \pm 1.6 \%$ versus $21.8 \pm 3.0 \%, p<0.02$; Group A vertebra: $15.9 \pm 1.6 \%$ versus $28.5 \pm 2.0 \%, p<0.02$; Group $C$ femur: $7.9 \pm 1.1 \%$ versus $29.6 \pm 3.5 \%, p<0.001$; Group C vertebra: $11.4 \pm 0.7 \%$ versus $37.1 \pm 1.9 \%, p<0.002$ ). Renal function tests were normal in the Group A diabetic rats and there was marked albuminuria in the Group C diabetic rats. Histologic changes in the kidneys were seen only in the Group C diabetic rats. Five of 15 Group C diabetic rats showed no albuminuria or histologic evidence of kidney damage. The bone density in this subgroup was reduced relative to controls to the same degree as that of the rats with renal damage. There was no evidence of capillary basement membrane thickening in the Group A diabetic rats. Our findings indicate that in the Cohen diabetic rat, osteoporosis precedes the onset of microangiopathy. Microangiopathy probably does not play an important role in the pathogenesis of osteoporosis in this animal model. (Lab Invest 2002, 82:1399-1405).
\end{abstract}

$T$ he aim of this study was to examine certain morphologic and morphometric changes in the bones of the Cohen diabetic rat, an animal model of type II diabetes mellitus, in an attempt to gain a better understanding of the biology of osteoporosis (OP) in type II diabetes mellitus. In human diabetic subjects, especially in the adult onset variety, the exact time of onset of diabetes and of complications such as OP is difficult to determine, and studies on bone of patients in the early stages of type II diabetes are lacking. Early changes in bone turnover are more easily observed and measured quantitatively in experimental animals.

The two major mechanisms in the development of complications in diabetes are metabolic/hormonal disturbances and microangiopathy. The pathogenesis of OP in type II diabetes mellitus is unknown. Although the possibility of an association between diabetic microangiopathy and OP has been proposed in a series of letters to the editor (Burkhardt et al, 1981;

DOI: 10.1097/01.LAB.0000032378.19165.E2

Received June 28, 2002.

Address reprint requests to: Dr. G. Amir, Department of Pathology, Hadassah University Hospital, Kiryat Hadassah, POB 12000, Jerusalem il-91120, Israel.E-mail address: gails@cc.huji.ac.il
McNair et al, 1981; Wientroub et al, 1980), no study correlating the presence and onset of these two complications of type II diabetes mellitus could be found in the English language literature.

Type II diabetic OP has long been regarded as a "low turnover" OP associated with depression of osteoblastic activity (Bouillon, 1991). There is wide acceptance of the view that increased bone resorption by osteoclasts does not play a role in this type of bone disease. This view was challenged recently by Hampson et al (1998) who found, using biochemical parameters, that bone resorption was increased in subjects with type II diabetes. Other workers have shown an initial loss of bone volume in type II diabetic subjects that later corrects itself (Krakauer et al, 1995). Histomorphometric studies of bone turnover performed at an early stage of the disease are likely to provide pertinent information regarding the pathogenesis of this form of OP and this is feasible in laboratory animals. In diabetic animal models, the osteoclast or lacunar number has been reported to be increased (Silberberg, 1987; Suzuki et al, 1998) and decreased (Hou et al, 1993; Suzuki et al, 1998). We assessed osteoblastic activity in the Cohen diabetic rat at different stages of the disease to determine a possible 
role for resorption of bone in the pathogenesis of diabetic OP in this model.

The diabetic sand rat (Psammomus obesus) has been shown to develop a greater degree of OP in weight-bearing bones than in the spine (Amir et al, 1991) and there is growing evidence that bone volume in human osteoporotic subjects varies in axial and appendicular bones (Amling et al, 1994; Riggs et al, 1981). To address this question, we compared the degree of OP in the axial and appendicular skeleton to determine which bones are more suitable for the study of $\mathrm{OP}$ in the Cohen diabetic rat.

In summary, the issues addressed in this study were (1) the temporal relationship between onset of OP and microangiopathy; (2) osteoblastic activity in different stages of OP; and (3) comparison between the degree of OP in the axial and appendicular skeleton.

\section{Results}

\section{Animals}

Male rats with fasting blood glucose levels higher than $16.6 \mathrm{mmol} / \mathrm{L}$ were used in this study. The controls were male age-matched healthy nondiabetic rats from downward-selected line (Table 1; see "Materials and Methods" for a description of the animal model).

The study included 25 Cohen diabetic rats and 16 control rats. The rats were divided into three groups according to the duration of diabetes, together with age-matched controls. Group A consisted of five rats with diabetes of 1 month's duration and four agematched control rats. Group B consisted of five rats with diabetes of 2 months' duration and five control rats. Group C consisted of 15 rats with diabetes of 7 to 8 months' duration and seven control rats. The mean body weight for all age groups was within normal limits for age. Group A and B rats were growing. Group C rats were postpubertal and no longer growing; residual epiphyseal cartilage was still apparent in their long bones but primary spongiosa was no longer seen.

\section{Biochemical Data}

Serum creatinine was not significantly altered in the Group A diabetic rats relative to controls $(59.4 \pm 1.4$

Table 1. Animal Groups

\begin{tabular}{|c|c|c|c|}
\hline & \multicolumn{3}{|c|}{ Study group } \\
\hline & A & B & C \\
\hline \multicolumn{4}{|l|}{ No. of rats } \\
\hline Control & 4 & 5 & 7 \\
\hline Diabetic & 5 & 5 & 15 \\
\hline \multicolumn{4}{|c|}{$\begin{array}{l}\text { Duration of diabetes } \\
\text { (months) }\end{array}$} \\
\hline Control & 2 & 3 & $7-8$ \\
\hline Diabetic & 2 & 3 & $7-8$ \\
\hline \multicolumn{4}{|c|}{ Weight of rats (grams) } \\
\hline Control & $176 \pm 2$ & $328 \pm 6$ & $341 \pm 8$ \\
\hline Diabetic & $174 \pm 2$ & $305 \pm 6$ & $300 \pm 6$ \\
\hline
\end{tabular}

versus $54.5 \pm 1.8 \mu \mathrm{mol} / \mathrm{L}$; not significant) (Table 2). In Groups B and C the serum creatinine was slightly higher in the diabetic rats relative to controls $(78.0 \pm$ 1.5 versus $60.2 \pm 2.5 \mu \mathrm{mol} / \mathrm{L}$ in Group B; $80.2 \pm 3.4$ versus $64.8 \pm 1.2 \mu \mathrm{mol} / \mathrm{L}$ in Group $\mathrm{C}$ ), but still well within normal limits for the rat (5.34 to $331.5 \mu \mathrm{mol} / \mathrm{L}$ ).

The urinary albumin excretion was not significantly altered in the young diabetic rats relative to the controls $(6.0 \pm 1.0$ versus $5.0 \pm 1.1 \mathrm{mg}$ per 24 hours; not significant). Increased albumin excretion became apparent in the diabetic rats in Group B (13.0 \pm 1.5 versus $4.4 \pm 1.0 \mathrm{mg}$ per 24 hours; $p<0.01$ ) and this increased with increasing duration of diabetes $(67.5 \pm$ 15.9 versus $9.1 \pm 0.7 \mathrm{mg}$ per 24 hours; $p<0.001$ in Group C).

Plasma calcium in the diabetic rats from Group C was within normal limits $(2.3 \pm 0.05 \mathrm{mmol} / \mathrm{L}$; normal range is 1.5 to $2.6 \mathrm{mmol} / \mathrm{L}$ ). Plasma phosphate was also within normal limits in the diabetic rats from Group C $(2.2 \pm 0.15 \mathrm{mmol} / \mathrm{L}$; normal range is 1.9 to $2.7 \mathrm{mmol} / \mathrm{L}$ ). Plasma phosphate was found to be slightly low in the control rats from Group C (1.8 \pm $0.06 \mathrm{mmol} / \mathrm{L})$.

\section{Renal Pathology}

Morphologic changes were not seen in the kidneys of the diabetic rats in Groups A and B on light microscopy. Advanced glomerular pathology (Grades 3-4) was observed in 10 of 15 diabetic animals in Group C. No changes were detected in the remaining five animals in Group C. No renal pathology was seen in any of the control rats.

\section{Capillary Basement Membrane}

The mean capillary basement membrane width of the diabetic animals was $47.1 \pm 1.3 \mathrm{~nm}$ and that of the control rats was $46.9 \pm 2.3 \mathrm{~nm}$ (not significant).

\section{Bone Parameters}

Trabecular Bone Volume. The mean trabecular bone volume (TBV) of distal femur (Fig. 1) and of vertebra (Fig. 2) was significantly reduced in the diabetic rats relative to controls in all three groups even when diabetes was of short duration, and this gap widened with increasing duration of diabetes (femora, Group A: $11.5 \pm 1.6 \%$ versus $21.8 \pm 3.0 \%, p<0.02$; Group B: $7.8 \pm 2.3 \%$ versus $26.2 \pm 2.5 \%, p<0.01$; Group C: $7.9 \pm 1.1 \%$ versus $29.6 \pm 3.5 \%, p<0.001$; Fig. 3 ; vertebrae, Group A: $15.9 \pm 1.6 \%$ versus $28.5 \pm 2.0 \%$, $p<0.02$; Group B: $15.1 \pm 2.6 \%$ versus $28.5 \pm 2.7 \%$, $p<0.02$; Group C: $11.4 \pm 0.7 \%$ versus $37.1 \pm 1.9 \%$, $p<0.002$ ).

When TBV of the diabetic rats was expressed as a percentage of TBV of the control rats, it was seen that the TBV in the femur was relatively less than that in the vertebra in the diabetic rats in all three groups (Group A: femur $52.8 \%$, vertebra $55.8 \%$; Group B: femur $29.8 \%$, vertebra $53.0 \%$; Group C: femur $26.7 \%$, vertebra $30.7 \%)$. In the control rats, bone volume in- 
Table 2. Biochemical Data for Diabetic and Control Rats (mean \pm SEM)

\begin{tabular}{ccccc}
\hline Group & $\begin{array}{c}\text { Serum creatinine } \\
(\mu \mathrm{mol} / \mathrm{L})\end{array}$ & $\begin{array}{c}\text { Urinary albumin } \\
(\mathrm{mg} / 24 \text { hours })\end{array}$ & $\begin{array}{c}\text { Serum calcium } \\
(\mathrm{mmol} / \mathrm{L})\end{array}$ & $\begin{array}{c}\text { Serum phosphate } \\
(\mathrm{mmol} / \mathrm{L})\end{array}$ \\
\hline A & & & - & - \\
$\quad$ Control & $54.5 \pm 1.8$ & $5.0 \pm 1.1$ & - & - \\
$\quad$ Diabetic & $59.4 \pm 1.4$ & $6.0 \pm 1.0(\mathrm{NS})$ & - & - \\
B Control & $60.2 \pm 2.5$ & $4.4 \pm 1.0$ & - & - \\
$\quad$ Diabetic & $78.0 \pm 1.5$ & $13.0 \pm 1.5(p<0.01)$ & & $1.8 \pm 0.06$ \\
C & & & $2.3 \pm 0.08$ & $2.2 \pm 0.15$ \\
$\quad$ Control & $64.8 \pm 1.2$ & $9.1 \pm 0.7$ & $2.3 \pm 0.05$ & \\
Diabetic & $80.2 \pm 3.4$ & $67.5 \pm 15.9(p<0.001)$ & & \\
\hline
\end{tabular}

NS, not significant.

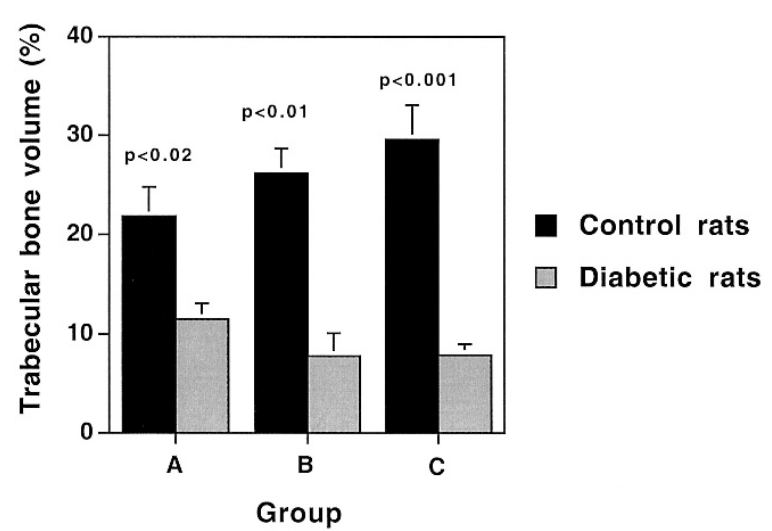

Figure 1.

Mean trabecular bone volume of distal femur \pm SEM in diabetic and control rats.

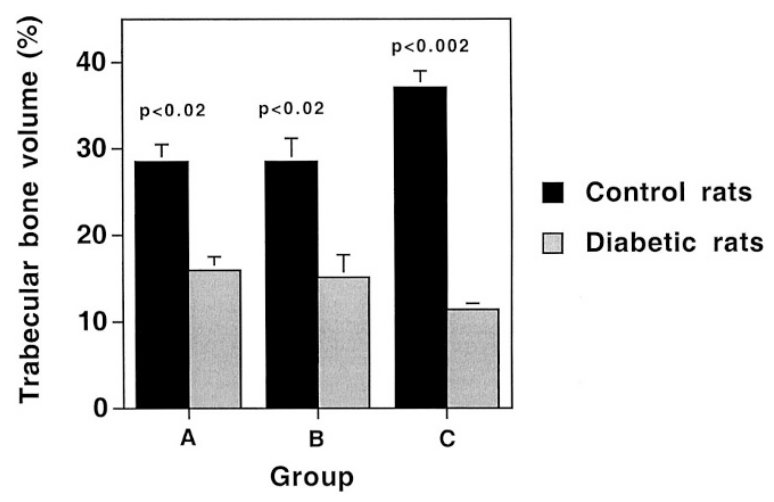

Figure 2.

Mean trabecular bone volume of vertebral bodies \pm SEM in diabetic and control rats.

creased progressively with age and was greater in the vertebra than in the femur in all three age groups.

Five of the 15 diabetic rats in Group C showed no histologic evidence of renal damage. In this subgroup, the TBV was also reduced to a similar degree to that of the 10 rats with histologic evidence of renal damage $(10.0 \pm 5.0 \%$ in the femur, $p<0.005$, and $13.0 \pm$ $2.0 \%$ in the vertebra, $p<0.005)$.

Cortical Thickness. There was no statistically significant difference between the cortical thickness of distal femora and vertebrae of the diabetic rats and the control rats (Table 3 ).

Howship's Lacunae. The mean corrected number of Howship's lacunae was significantly higher in the diabetic rats in Groups A and B relative to the control rats (Group A: $7.8 \pm 1.3$ versus $1.7 \pm 0.5$ lacunae, $p<$ 0.01 ; Group B: $6.3 \pm 0.9$ versus $3.5 \pm 0.6$ lacunae, $p$ $<0.05)$. In Group C, the number of Howship's lacunae was identical in the study and control groups. Morphologic features of hyperparathyroidism, such as dissecting osteitis, increased osteoblastic activity, and peritrabecular fibrosis were not seen in any of the groups (Table 3).

\section{Discussion}

The association of type I diabetes mellitus and OP has long been recognized (Forst et al, 1995; Silberberg, 1986). The data on OP in patients with type II (noninsulin-dependent) diabetes is less clear and frequently contradictory. Increased (Barrett-Connor and Holbrook, 1992; Isaia et al, 1987; Johnston et al, 1985), normal (Giacca et al, 1988; Weinstock et al, 1989), and decreased bone volume (Isaia at al, 1987; Ishida et al, 1985; Levin et al, 1976) have been observed. This may be in part due to the fact that most patients with type II diabetes are overweight. Obesity per se tends to be associated with increased bone volume and is thus a confounding factor in the study of OP in obese diabetic patients (Albala et al, 1996).

Studies of OP in animal models of type II diabetes are also confounded by the fact that almost all of these models develop obesity. A second disadvantage of most animal models of type II diabetes is their failure to develop convincing evidence of microangiopathy, which is a major complication of human diabetes mellitus.

The Cohen diabetic rat is a genetically selected nonobese animal model of type II diabetes mellitus that has been shown to develop both OP and evidence of microangiopathy (nephropathy and retinopathy) (Yanko et al, 1975). It is therefore considered a suitable animal model for studying OP in type II diabetes mellitus.

Our findings confirm the development of marked osteopenia in the Cohen diabetic rat in all three 

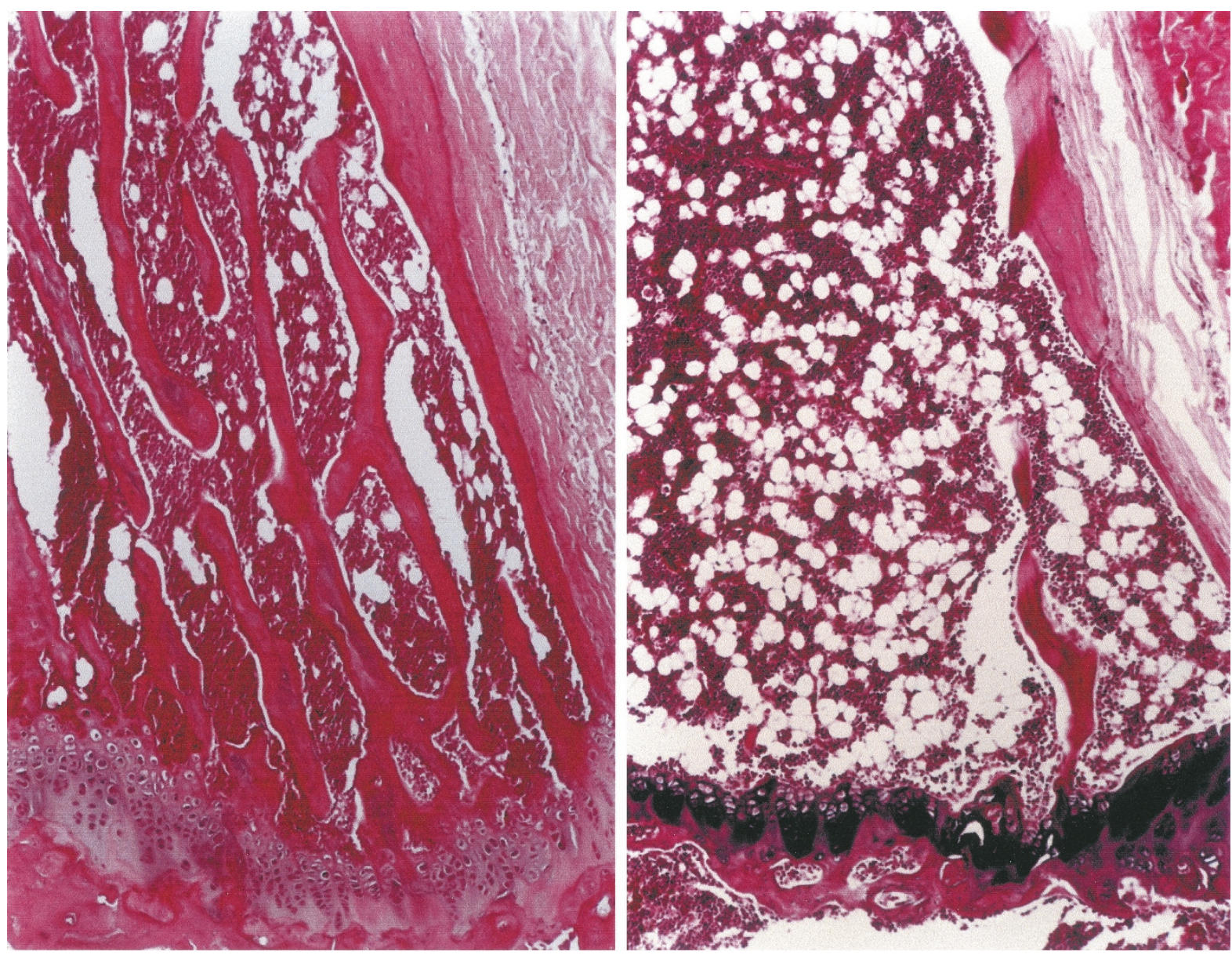

\section{Figure 3.}

Histologic appearance of the metaphyseal area of distal femur. Left, Control rat from Group C showing dense trabecular bone formation. Right, Diabetic rat from Group $C$ showing marked decrease in trabecular bone. Hematoxylin-eosin stained; original magnification, $\times 40$.

Table 3. Histomorphometric Data for Diabetic and Control Rats (mean \pm SEM)

\begin{tabular}{clll}
\hline & \multicolumn{2}{c}{ Cortical thickness $(\mathrm{mm})$} & \\
\cline { 2 - 3 } Group & \multicolumn{1}{c}{ Femur } & \multicolumn{1}{c}{ Vertebra } & Lacunae/TBV \\
\hline A & & & \\
Control & $0.19 \pm 0.02(\mathrm{NS})$ & $0.12 \pm 0.01(\mathrm{NS})$ & $1.7 \pm 0.5(p<0.01)$ \\
Diabetic & $0.16 \pm 0.02$ & $0.09 \pm 0.01$ & $7.8 \pm 1.3$ \\
B Control & $0.27 \pm 0.04$ (NS) & $0.15 \pm 0.02$ (NS) & $3.5 \pm 0.6(p<0.05)$ \\
Diabetic & $0.40 \pm 0.09$ & $0.13 \pm 0.02$ & $6.3 \pm 0.9$ \\
C Control & $0.29 \pm 0.01$ (NS) & $0.11 \pm 0.01$ (NS) & $2.3 \pm 0.8$ (NS) \\
Diabetic & $0.31 \pm 0.02$ & $0.11 \pm 0.01$ & $2.3 \pm 0.8$ \\
\hline
\end{tabular}

TBV, trabecular bone volume; NS, not significant.

groups. This finding is compatible with OP, but because of the evidence of renal changes in the diabetic rats in Groups B and C, secondary hyperparathyroidism and osteomalacia must be considered in the differential diagnosis. Both can be excluded for the following reasons:

Secondary hyperparathyroidism is unlikely to have made a significant contribution to the bony changes because there was evidence of glomerular disease but not of renal failure in Group B (albuminuria) and Group C (albuminuria and glomerular pathology), and the diabetic rats in Group C had normal serum calcium and phosphate. Furthermore the trabecular bone of the diabetic rats did not show histologic features of hyperparathyroidism. The number of Howship's lacunae observed in the trabecular bone of the diabetic rats decreased with increasing duration of diabetes and increasing evidence of renal involvement, which is 
the opposite of what would be expected to occur in secondary hyperparathyroidism. It is of interest that a relatively low prevalence of secondary hyperparathyroidism has been reported in human diabetic subjects with chronic renal failure compared with nondiabetic patients with chronic renal failure (Malberti et al, 2001).

Osteomalacia can also be excluded because it is characterized by decreased mineralized bone but normal amount of bone matrix, whereas in this study the entire TBV was decreased in the diabetic rats.

The OP was progressive and was seen both in the growing and in the postpubertal diabetic rats that were no longer growing. The decrease in bone volume was striking in the rats with the shortest duration of diabetes. The bone volume of the distal femur in the Cohen diabetic rats in this group was just over half that of the age- and weight-matched control rats. The osteopenia was slowly progressive in the diabetic rats and this was offset by a progressive increase in bone density with age in the control rats, so that the relative reduction of bone density was greatest in the older diabetic rats.

How did this early onset osteopenia correlate with the onset of microangiopathy? The rats with the shortest duration of diabetes did not show biochemical or morphologic evidence of microangiopathy despite the fact that they had already developed significant OP. Even ultrastructural examination of capillaries of Group A rats failed to show early evidence of microvascular pathology. Most of the rats with diabetes of longer duration (Group C) showed evidence of glomerular disease, but there was no correlation between the presence of nephropathy and the degree of loss of bone volume in these animals. The onset of marked OP in the young animals before microvascular changes were evident and the lack of influence of renal disease on the degree of OP suggest that microangiopathy does not play a major role in the pathogenesis of OP in this model of type II diabetes.

The femora of the diabetic animals showed more severe OP than the vertebral bodies. The femora of the control rats also contained relatively less trabecular bone than the vertebrae of the control rats. The cortical bone of the femora was thicker than that of the vertebrae in all three groups, but there was no difference between cortical thickness of diabetic rats and control rats. This relative increase in vertebral trabecular bone volume in both diabetic and control animals is probably a compensatory mechanism for the relatively thinner cortical bone normally found in the vertebral bodies. This may be exacerbated by the phenomenon of hyperostotic spondylosis that is one of the lesser-known complications of diabetes mellitus (Hajkova et al, 1965), and has also been described in animal models of diabetes mellitus (Silberberg and Gerritsen, 1976).

Our study suggests that femoral bone is as good as if not better than axial bone for assessing the effects of diabetes on TBV in this model by histomorphometric methods.

Histomorphometric techniques are more accurate than conventional imaging methods such as dual- energy $\mathbf{x}$-ray absorptiometry for quantitating the trabecular bone compartment because it is possible to exclude cortical bone, which is minimally affected by $\mathrm{OP}$, from the assessment. Dual-energy $\mathrm{x}$-ray absorptiometry does not distinguish between cortical and trabecular bone and therefore gives a falsely high reading for appendicular bone due to its relatively greater component of cortical bone (Lundeen et al, 2001). Recently, more sophisticated high-resolution techniques such as microcomputed tomography have been developed that permit distinction between trabecular and cortical bone (Muller et al, 1998). Assessment of TBV by this technique has been found to correlate well with histomorphometry (Alexander et al, 2001).

The finding of a significantly increased number of Howship's lacunae in the younger diabetic rats in our study contrasts with Silberberg's (1990) observation of a normal number of osteoclasts and a decreased number of osteoclast-free lacunae in vertebral bone of Cohen diabetic rats. This anomaly could be accounted for by the fact that older rats were used in that study and no correction was made for reduced trabecular bone surface area of the diabetic osteopenic rats. Our finding of early osteoclastic mobilization correlates with the early onset of osteopenia observed and does not correlate with the late onset of microangiopathy. This suggests a role for increased osteoclastic mobilization as an early event in the pathogenesis of OP in these type II diabetic animals. Because the Cohen diabetic rat exhibits similar complications to those seen in human type II diabetes mellitus, increased osteoclastic activity may be a factor in the pathogenesis of OP in human type II diabetic subjects before it becomes clinically apparent.

\section{Conclusion}

The Cohen diabetic rat is a good model for examining the effects of type II diabetes on bone volume. By histomorphometric techniques, femoral bones are a better index of OP than vertebral bodies. The onset of $\mathrm{OP}$ is early, before changes of microangiopathy are evident. This suggests that microangiopathy is not a major factor in the pathogenesis of OP in this diabetic animal model. There is evidence that increased bone resorption by osteoclasts may play a role in the onset of $\mathrm{OP}$ in the Cohen diabetic rat.

\section{Materials and Methods}

\section{Animals}

The Cohen diabetic rat shares common genetic, metabolic, and morphologic features with human noninsulin-dependent diabetes (Cohen et al, 1995) (Table 1). It is a nonobese model of type II diabetes induced by genetic selection of healthy "Sabra" rats from the Hebrew University Strain. These rats are fed a high-sucrose copper-poor diet, starting after weaning. Offspring with abnormal glucose tolerance are inbred (upward selection). These animals develop hyperglycemia and glycosuria at the age of 1 month and 
have been shown to develop diabetic vascular complications. The downward-selected line are healthy rats, with no genetic predisposition to develop diabetes, that remain normoglycemic on a high-sucrose copper-poor diet (Cohen et al, 1972). Both study and control rats reach puberty after 45 to 75 days and have a lifespan of 2 to 3 years.

The animals were killed under deep pentobarbital anesthesia. Microangiopathy was assessed by renal function tests and pathologic evaluation of the kidneys. In addition, ultrastructural assessment of capillary basement membrane thickness was performed on six rats in Group A. Bone parameters were assessed by morphometric techniques.

\section{Biochemical Assay}

Serum creatinine and urinary albumin were measured as previously described in this animal model (Cohen et al, 1995). Serum calcium and phosphate were measured by routine hospital testing in five diabetic rats and five control rats from Group C.

\section{Pathologic Evaluation}

Kidney. Whole transverse sections of both kidneys were evaluated blindly by one of the pathologists (ER) and approximately 300 glomeruli were screened in each case. The degree of glomerulosclerosis was graded according to the number of glomeruli involved (focal or generalized) and the extent of glomerular involvement (segmental or diffuse). The morphologic changes were graded on a scale of 0 to 4 , as previously described (Cohen et al, 1995). Briefly, in Grades 1 and 2 there is focal involvement of the glomeruli (15\% to $50 \%$ ), in Grade 3 there is more generalized involvement, and in Grade 4 tubular or interstitial changes or xanthomatous and/or lipohyaline glomerular changes are seen as well.

Capillary Basement Membrane. Tissue was available for electron microscopy from soft tissue adjacent to femoral bone of three control rats and three diabetic rats from Group A. Immediately after the rats were killed, tissue was dissected off, fixed in glutaraldehyde, and processed for electron microscopy. Two blocks were prepared from each animal and five transversely cut capillaries were examined from each block. Ten measurements were performed on each capillary, as described previously (Yodaiken and Pardo, 1975); the mean results were expressed in nanometers $\pm \mathrm{SD}$.

Bones. Whole femora together with the knee joints were removed from the carcasses as well as a length of lumbar spine including L1, 2, and 3. After dissecting off the soft tissue, the bones were fixed in $10 \%$ formalin and decalcified in a solution of Rapid Bone Decalcifier (Apex Engineering Products, Plainfield, Illinois). After decalcification, the bones were split. The distal femora was bisected in the coronal plane and the lumbar vertebrae were split sagittally. The bones were dehydrated, cleared in methyl salicylate, and embedded in paraffin according to a routine method.
Semiserial sections from both halves of each bone were cut $5 \mu \mathrm{m}$ thick and stained with hematoxylineosin and Masson trichrome.

\section{Bone Parameters Examined Blindly by GA}

Trabecular Bone Volume. The surface area of the trabecular bone in the metaphyseal area of the distal femur and the metaphyseal area of thoracic vertebra was assessed. The metaphyseal region was chosen because this is the area of active bone growth. Trabecular surface area was measured on a semiautomatic computerized image analysis system, Quantimet 570 (Cambridge Instruments, Northwich, United Kingdom) attached to an optical microscope using a $\times 10$ objective lens. Three histologic sections of bone from distal femur and three sections of vertebral bone were assessed from each rat. Two vertebral bodies were included in each section of vertebral bone. The metaphyseal area of the femur and the vertebra was defined as the area extending from the border between the primary and secondary spongiosa (adjacent to the growth plate) to a point representing the distance of a standard frame on the video screen from the cortico-epiphyseal junction (representing the metaphyseal-diaphyseal junction) at $\times 4$ magnification. The endosteal surfaces of the cortical bone defined the lateral and medial borders. The outline of the metaphyseal trabecular bone was traced manually with the aid of an optical mouse and the trabecular bone surface area was computed. The total surface area of the metaphyses (as defined above) was also computed by means of manual tracing. Trabecular bone surface area was assessed as a percentage of the total surface area of the metaphyseal region. Results were expressed as TBV in accordance with the Delesse principle (Delesse, 1848).

Cortical Thickness. The cortical thickness of the distal femora and the vertebral bodies was traced manually and computed on the Quantimet. Histologic sections cut at three different levels were examined from each rat and five measurements were made on each slide. The measurements were performed in the area of the diaphyseal-metaphyseal border.

Osteoclastic Activity. The number of well-formed Howship's lacunae in the metaphyseal region of the distal femora was counted manually at $\times 10$ magnification (area of field, $2.54 \mathrm{~mm}^{2}$ ) and expressed as osteoclast lacunae per square millimeter. To compensate for differences in bone volume between study and control animals, the results were expressed as a fraction of the TBV as measured above (lacunae/TBV). Measurements were performed on all of the diabetic rats in Groups A and B, 9 of 15 diabetic rats in Group $\mathrm{C}$, and all of the control rats.

\section{Statistical Analysis}

The results were analyzed statistically by the MannWhitney test. 


\section{Acknowledgement}

We would like to thank Mrs. Mallie Sapir for excellent technical assistance.

\section{References}

Albala C, Yanez M, Devoto E, Sostin C, Zeballos L, and Santos JL (1996). Obesity as a protective factor for postmenopausal osteoporosis. Int $\mathrm{J}$ Obes Relat Metab Disord 20:1027-1032.

Alexander JM, Bab I, Fish S, Muller R, Uchiyama T, Gronowicz G, Nahounou M, Thao Q, White DW, Chorev M, Gazit D, and Rosenblatt M (2001). Human parathyroid hormone 1-34 reverses bone loss in ovariectomized mice. J Bone Miner Res 16:1665-1673.

Amir G, Adler JH, and Menczel J (1991). Histomorphometric analysis of weight-bearing bones of diabetic and nondiabetic sandrats (Psammomys obesus). Diabetes Res 17: 135-137.

Amling M, Grote HJ, Posl M, Hahn M, and Delling G (1994). Polyostotic heterogeneity of the spine in osteoporosis. Quantitative analysis and three-dimensional morphology. Bone Miner 27:193-208.

Barrett-Connor E and Holbrook T-L (1992). Sex differences in osteoporosis in older adults with non-insulin-dependent diabetes mellitus. JAMA 268:3333-3337.

Bouillon R (1991). Diabetic bone disease (Editorial). Calcif Tissue Int 49:155-160.

Burkhardt R, Moser W, Bartl R, and Mahl G (1981). Is diabetic osteoporosis due to microangiopathy? (Letter). Lancet 1:844.

Cohen AM, Teitelbaum A, and Saliternik P (1972). Genetics and diet as factors in the development of diabetes mellitus. Metabolism 21:235-240.

Cohen AM, Wald H, Popovtzer M, and Rosenmann E (1995). Effect of myo-inositol supplementation on the development of renal pathological changes in the Cohen diabetic (type 2) rat. Diabetologia 38:899-905.

Delesse MA (1848). Procede mechanique pour determiner la composition das roches. Ann Mines 13:379-388.

Forst T, Pfutzner A, and Kann P (1995). Peripheral osteopenia in adult patients with insulin-dependent diabetes mellitus. Diabet Med 12:874-879.

Giacca A, Fassina A, Caviezel F, Cattaneo AG, Caldirola G, and Pozza G (1988). Bone mineral density in diabetes mellitus. Bone 9:29-36.

Hajkova Z, Streda A, and Skrha F (1965). Hyperostotic spondylosis and diabetes mellitus. Ann Rheum Dis 24:536543.

Hampson G, Evans C, Petitt RJ, Evans WD, Woodhead SJ, Peters JR, and Ralston SH (1998). Bone mineral density, collagen type 1 alpha 1 genotypes and bone turnover in premenopausal women with diabetes mellitus. Diabetologia 41:1314-1320.

Hou JC, Zernicke RF, and Barnard RJ (1993). Effects of severe diabetes and insulin on the femoral neck of the immature rat. J Orthop Res 11:263-271.

Isaia G, Bodrato L, Carlevatto V, Mussetta M, Salamano G, and Molinatti GM (1987). Osteoporosis in type II diabetes. Acta Diabetol Lat 24:305-310.
Ishida $\mathrm{H}$, Seino $\mathrm{Y}$, Matsukura S, Ikeda M, Yawata M, Yamashita G, Ishizuka S, and Imura H (1985). Diabetic osteopenia and circulating levels of vitamin $D$ metabolites in type 2 (non-insulin-dependent) diabetes. Metabolism 34:797-801.

Johnston CC, Hui SL, and Longcope C (1985). Bone mass and sex steroid concentrations in postmenopausal Caucasian diabetics. Metabolism 34:544-550.

Krakauer JC, McKenna MJ, Buderer NF, Rao DS, Whitehouse FW, and Parfitt AM (1995). Bone loss and bone turnover in diabetes. Diabetes 44:775-782.

Levin ME, Boisseau V-C, and Avioli LV (1976). Effects of diabetes mellitus on bone mass in juvenile and adult-onset diabetes. N Engl J Med 294:241-245.

Lundeen GA, Knecht EG, Vajda RD, Bloebaum AA, and Hofman AA (2001). The contribution of cortical and cancellous bone to dual-energy $\mathrm{X}$-ray absorptiometry measurements in the female proximal femur. Osteoporos Int 12:192-198.

Malberti F, Marcelli D, Conte F, Limido A, Spotti D, and Locatelli $F$ (2001). Parathroidectomy in patients on renal replacement therapy: An epidemiologic study. J Am Soc Nephrol 12:1242-1248.

McNair P, Christensen MS, Christiansen C, Madsbad S, and Transbol I (1981). Is diabetic osteoporosis due to microangiopathy? (Letter). Lancet 1:1271.

Muller R, Campenhout H, Van Damme B, Van Der Perre G, Dequeker J, Hilderbrand T, and Ruegsegger P (1998). Morphometric analysis of human bone biopsies: A quantitative structural comparison of histological sections and microcomputed tomography. Bone 23:59-66.

Riggs BL, Wahner HW, Dunn WL, Mazess RB, Offord KP, and Melton LJ (1981). Differential changes in bone mineral density of the appendicular and axial skeleton with aging: Relationship to spinal osteoporosis. J Clin Invest 67:328-335.

Silberberg $R$ (1986). The skeleton in diabetes mellitus: A review of the literature. Diabetes Res 3:329-338.

Silberberg R (1987). Morphometric analysis of cancellous bone of young diabetic and non-diabetic sand rats (Psammomys obesus). Diabetes Res 5:149-151.

Silberberg R (1990). Osteopathy and arthropathy. In: Cohen $\mathrm{AM}$ and Rosenmann E, editors. The Cohen diabetic rat. Basel: Karger, 87-100.

Silberberg R and Gerritsen G (1976). Aging changes in intervertebral discs and spondylosis in Chinese hamsters. Diabetes 25:477-483.

Suzuki K, Ishida H, Takeshita N, Taguchi Y, Sugimoto C, Nosaka K, and Seino $Y$ (1998). Circulating levels of tartrate-resistant acid phosphatase in rat models of non-insulin-dependent diabetes mellitus. J Diabet Complications 12:176-180.

Weinstock RS, Goland RS, Shane E, Clemens TL, Lindsay R, and Bilezikian JP (1989). Bone mineral density in women with type II diabetes mellitus. J Bone Miner Res 4:97-101.

Wientroub S, Eisenberg D, Tardiman R, Weissman SL, and Salama R (1980). Is diabetic osteoporosis due to microangiopathy? (Letter). Lancet 2:983.

Yanko L, Rosenmann E, and Cohen AM (1975). A correlative study on the occurrence of retinopathy and nephropathy in sucrose fed diabetic rats. Acta Diabetol Lat 12:52-56.

Yodaiken RE and Pardo V (1975). Diabetic capillaropathy. Human Pathol 6:455-465. 